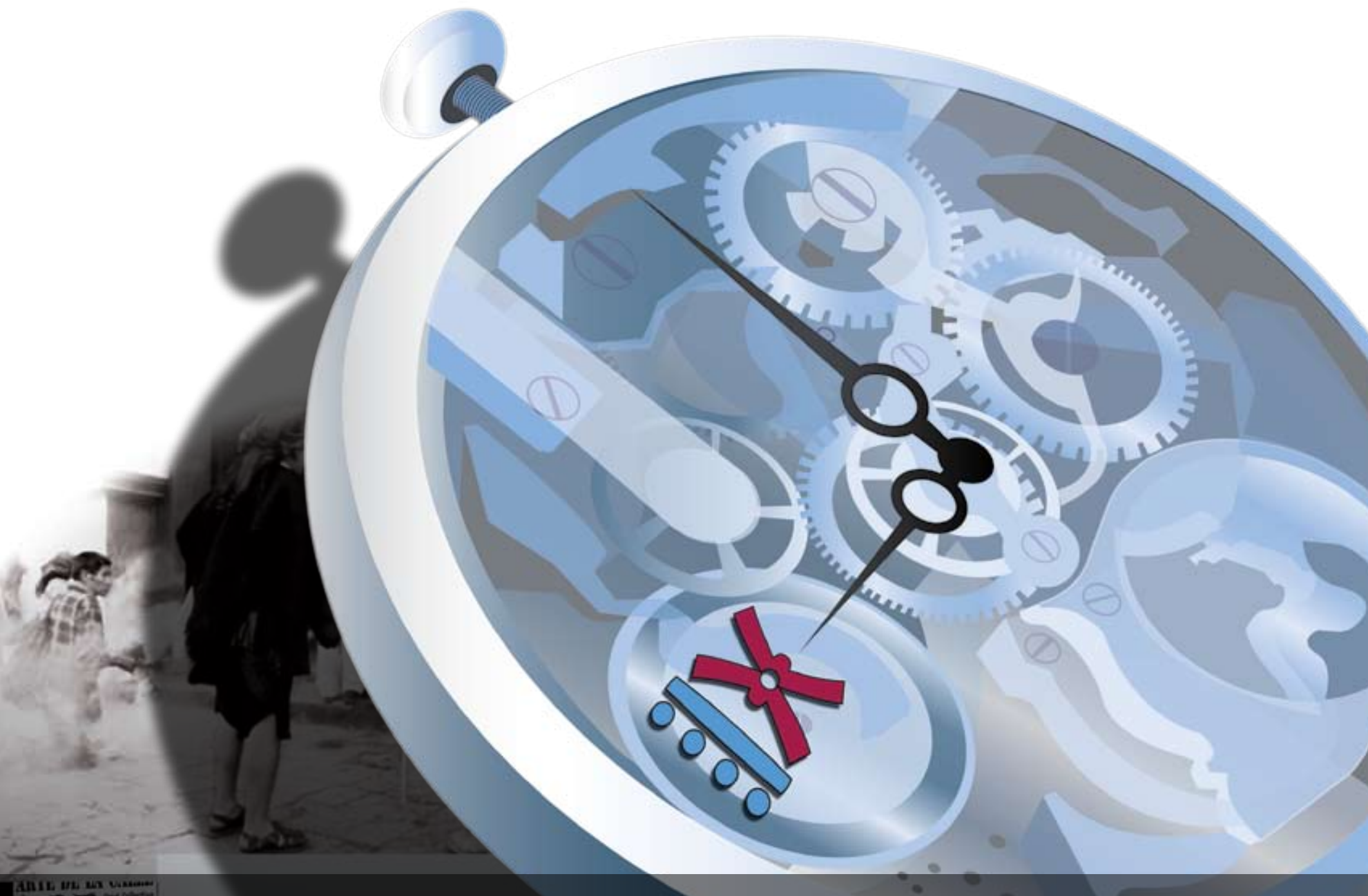

O $99^{\circ}$ C O N G R S O $Q 2$ CENTROAMERICANO DE HISTORIA

Universidad de Costa Rica ISSN 1409-469X

Fecha de recepción: 15 de mayo 2008 Fecha de aceptación: 30 de mayo 2008

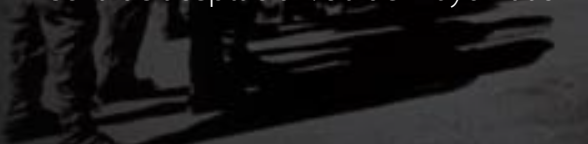

Las relaciones entre madres e hijas en cuentos de escritoras mexicanas contemporáneas

Miembros del Consejo Editorial:

Dr. Ronny Viales, Dr. Juan José Marín

Editores Técnicos:

Allan Fonseca, Andrés Cruz, Gabriela Soto
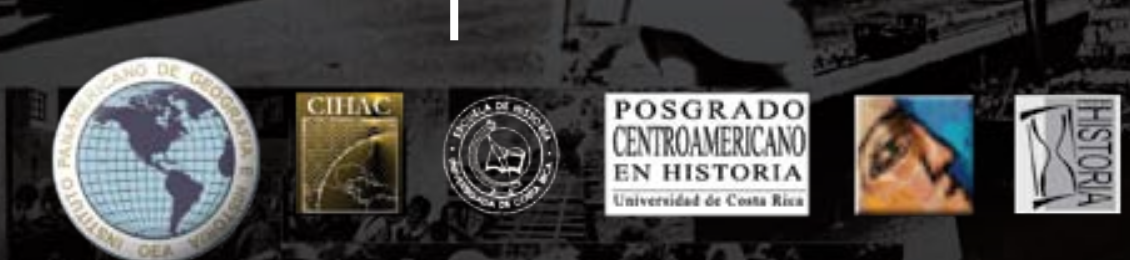
Indexaciones: Repositorio de Revistas UCR, DIALNET, Latindex, REDALYC Directorio y recolector de recursos digitales del Ministerio de Cultura de España, Directory of Open Access Journals. Diálogos Revista Electrónica de Historia ISSN 1409-469X. Número especial 2008. Dirección web: http://historia.fcs.ucr.ac.cr/dialogos.htm

\title{
Las relaciones entre madres e hijas en cuentos de escritoras mexicanas contemporáneas
}

\author{
María Adriana Velasco Marín.
}

Dirección postal: Arboledas de San Ignacio. Calzada San Ignacio Poniente, No. 39. Puebla, México C.P. 72590.

Tel: 01152222334687.

Correo: tichomar@yahoo.com.mx. Alumna del Doctorado en Ciencias del Lenguaje de la Benemérita Universidad Autónoma de Puebla. Profesora de tiempo parcial de la Universidad de las Américas. 


\section{Introducción}

El surgimiento gradual de textos literarios escritos por mujeres incluye otras experiencias y permite, como señala Marianne Hirsch ${ }^{1}$, examinar y cuestionar diversas tramas sobre madres e hijas para descubrir no únicamente determinadas ideologías sobre la maternidad plasmadas en ellas, sino además patrones narrativos que ponen en tela de juicio construcciones convencionales. Hirsch señala la importancia de una serie de preguntas eje que es preciso intentar responder para revelar el verdadero entramado en el que se construyen las relaciones entre madres e hijas:

¿Qué es una madre? ¿Qué es lo materno/maternal? (...)¿La maternidad es experiencia o institución? ¿Es biológica o cultural? ¿Está la madre presente o ausente, sola o dividida, coludida con el patriarcado o en lucha contra él, es la madre conformista o subversiva? ${ }^{2}$

Las posibles respuestas a estas preguntas dan cuenta de una diversidad en la que poco se ha reparado. Las escritoras mexicanas han trabajado abundantemente sobre este tema, imprescindible en la conformación de la identidad femenina. El criterio que rigió la selección de los textos fue que la trama de los mismos permitiera estudiar las ideologías sobre la maternidad presentes en ellos, así como descubrir los modelos narrativos que cuestionan las creencias predominantes, tales como "el amor incondicional" entre madres e hijas, la maternidad como "punto culminante" en la vida de toda mujer, el desarrollo femenino a partir de la identificación con la madre, la interacción de las distintas voces femeninas (abuela, madre, nieta) en las tramas y la evasión de lo materno. Las escritoras y los títulos de los cuentos que apoyarán nuestro análisis se han agrupado en dos bloques. En el primero ubicamos los textos donde la hija se presenta en la niñez o en la adolescencia, aunque posteriormente la narración se desarrolle progresivamente hacia la 
madurez de este personaje. En el segundo grupo se incluyen las narraciones en las que la hija es presentada como una persona adulta, a pesar de que durante el desarrollo de la historia se muestren episodios de su infancia y/o adolescencia.

Una vez señaladas las principales constantes de ambos grupos será posible lograr algunas conclusiones en cuanto a la relación entre miradas, voces hegemónicas y voces disidentes que muestran el conflicto entre los discursos que hacen posible cuestionar, dentro de la estructura de los textos literarios, los códigos culturales dominantes. En particular, recurriremos a la clasificación del narrador a partir del nivel narrativo en que este se encuentra, según la propuesta de G. Genette3. También será pertinente para el análisis de los cuentos la aplicación del concepto de focalización; es decir, la ubicación de la mirada que observa los hechos narrados, lo que deriva de la circunstancia del observador y de la información que procura y expone su particular punto de vista. El enfoque narratológico servirá, pues, para enmarcar las características específicas de la estructura de cada uno de los cuentos que se analizarán.

\section{Desarrollo}

A partir del cuestionamiento planteado por Marianne Hirsch4 del patrón de "family romance", que Freud señala como universal y que la autora indica que no es un solo patrón sino patrones que varían para los escritores y las escritoras según la época y la cultura, se incluirá la perspectiva de la crítica literaria feminista actual, ya que como menciona Raquel Gutiérrez Estupiñán5 una de las tareas principales de dicha crítica es indagar las formas en que la literatura escrita por mujeres ha respondido, mediante la parodia, ante los patrones establecidos por la tradición vigente.

Marianne Hirsch es una de las pocas autoras que se han ocupado específicamente de la relación entre madre e hija en la literatura escrita por mujeres. Si bien enfoca obras de la literatura 
norteamericana y europea, será muy útil para nuestro estudio, ya que ofrece una guía de análisis muy completa y específica, lo que evitará que nos desviemos de los fines de esta investigación. Se efectuarán los ajustes pertinentes que nos permitan adaptar esta teoría a nuestro corpus, pues lo que interesa es indagar las características de esa interacción en la literatura mexicana.

El análisis de algunos aspectos del tema por estudiar exige recurrir a una perspectiva psicoanalítica para entender conceptos tales como: identidad, introspección, simbiosis, etapa preedípica, entre otros; por lo antes expuesto, las reflexiones de Nancy Chodorow (Barcelona, 1984), Alicia Lombardi (Buenos Aires, 1990), Norma Ferro (Madrid, 1991) y Nancy Friday (Barcelona, 1989) respecto al tema serán indispensables. Los cuentos que conforman el corpus completo son, para el primer grupo: "Lo que no se comprende", de Inés Arredondo; "La moneda de plata", de Carmen Báez; "Abril”, "Serena”, "Uka”, "Widad” y “Zhu”, de Rosaura Barahona; “Tres nudos en la red", de Rosario Castellanos; "La otra cara de la moneda", de Martha Cerda; "Trazos", de Amelia Domínguez; "La tía Carlota", de Guadalupe Dueñas; "Marichú", de Beatriz Espejo; "Respuestas al viento", de Alicia García; "Unión familiar”, de Coty Hernández; "Las muñecas”, de María de Lourdes Morales; "La madre", de Angelina Muñiz; "La niña Elvira" y "Joven madre", de María Luisa Puga.

El segundo grupo se encuentra conformado por: "Canción de cuna", de Inés Arredondo; "Cabecita blanca", de Rosario Castellanos; "La celda”, de Amparo Dávila; "Un error de apreciación”, de Teresa Dey; "El eterno teatro", de Brianda Domecq; "El monograma de oro", de Beatriz Espejo; "Enigma”, de María de Lourdes Morales; "Las siete ya van a dar”, de Rosa Nissán; "La última cena”, de Cristina Pacheco y "Equilibrio", de Antonieta Rivas Mercado.

Las constantes que se observan en la anterior selección de veintiocho cuentos se conforman 
en seis apartados que se expondrán a continuación; es necesario indicar que algunos cuentos aparecerán en dos apartados o más.

\section{Voces y miradas (aniquilación de la voz materna, incomunicación de madres/hijas)}

Del análisis narratológico de estos textos emergen tres tipos de voces narrativas. A la vanguardia toma la palabra un narrador no marcado en tercera persona, implícito, heterodiegético y extradiegético ${ }^{6}$. En segundo lugar se encuentra la voz del personaje cuyo rol es el de hija, es un narrador explícito, homodiegético e intradiegético. Por último, la madre toma la palabra como un narrador explícito, homodiegético e intradiegético. El hecho de que la voz de la madre sea desplazada hasta un tercer sitio induce a pensar en el silenciamiento que se refleja en el acto narrativo y en la trama de las historias, donde esta voz es acallada, bloqueada, mutilada -a veces hasta la ausencia absoluta- por el padre, la hija, ella misma y muchas veces también su madre; veamos a continuación algunos ejemplos.

En "Cabecita Blanca", de Rosario Castellanos descubrimos a doña Justina, viuda de Juan Carlos con quien tuvo tres hijos: Carmela, Lupe y Luisito. La madre mantiene buenas relaciones con su hijo, todo lo hecho por él resulta de su agrado; sin embargo de las hijas no hay mucho que esperar. La madre de doña Justina el día de la boda de esta le aconseja el mutismo si desea tener un matrimonio feliz.

[...] Y que la virtud suprema que había que practicar si se quería merecer la palma del martirio (ya que a la virginidad se había renunciado automáticamente al tomar el estado de casada) era la virtud de la prudencia. Y la señora Justina entendió por prudencia el silencio, el asentimiento, la sumisión. ${ }^{7}$

En "Equilibrio", de Antonieta Rivas Mercado, una mujer desea que su hija elija un destino propio 
y por lo tanto decide ayudarla a escapar aunque ella se quede a enfrentar al padre de la joven, un hombre autoritario y castrante. En este texto es posible observar cómo el padre continuamente cierra los espacios comunicativos con su esposa, tomando él en exclusiva la palabra.

-¡Cállate ! -ordenó imperativo-, tú nada sabes de ésas, tú eres buena, honrada. No hables. Ella no replicó. Acostumbraba doblegarse bajo el peso de aquella aplastante superioridad. ${ }^{8}$

En "El Monograma de oro", de Beatriz Espejo presenciamos otro matrimonio unido por los monólogos del marido. En este cuento cobra singular relevancia un padre enfermo que "decide no morirse" hasta ver a su hija casada con el hombre que a él le parezca adecuado y, por lo tanto, se niega a aceptar que su hija ya haya elegido a una pareja. La madre presencia en silencio el enfrentamiento de ambos, para después de la muerte del padre adoptar la misma actitud impositiva.

El cuarto se volvía una vitrina tras cuyas puertas encristaladas doña Beatriz se acostumbró a expiar la humillación de un matrimonio sin diálogo. ${ }^{9}$

Por lo tanto, no se accede a la relación madre-hija de una manera completa sino parcial, coartada por la intervención paterna. La voz de la madre es necesaria para saber su perspectiva; como señala Hirsch10, la historia del desarrollo femenino, en la ficción y en la teoría, requiere ser escrita por la voz de las madres y de las hijas.

Aunque el diálogo nos permita disipar la ira de una forma menos dañina, la mordaza se impone. En escasas ocasiones la madre rompe con las ataduras para dar paso a un grito de rebeldía, aunque este sea pasado por alto. Sus ideas son estrictamente suyas, nadie las conoce pues su discurso es marginado. Adrienne Rich11 indica que muchas hijas guardan rencor hacia sus madres por 
su pasividad para aceptar cualquier cosa. Así, la conversión de la madre en víctima no solo la humilla a ella sino que mutila a la hija que la observa en busca de claves para conocer qué significa ser mujer.

Una preocupación constante en todos los cuentos, favorecida por la presentación de un narrador femenino en primera persona, es la introspección de los personajes madre e hija, que las lleva a analizarse a sí mismas y su relación con la otra. ¿Cuál es el verdadero lazo que las une?, porque, aunque el sentimiento que las estrecha a veces resulta poco gratificante y hasta destructivo, no se permite pensar en la ruptura. Lo importante es no alterar las relaciones familiares, sin considerar que lo anterior pueda crearles sentimientos de culpa y de rencor.

La relación tira en dos direcciones contrarias y se genera lo que Nancy Friday ${ }^{12}$ define como simbiosis malsana. La autora explica que la "simbiosis" es la unión estrecha del niño(a) con su madre; el feto se halla en una simbiosis física con la madre y ella está en simbiosis psicológica con él; en el momento de nacer el bebé necesita estar cerca, casi de una manera sofocante, con el cuerpo que lo nutrió. Sin embargo, después de los tres años debe darse la separación para que el niño(a) se desarrolle plenamente como individuo. Esta separación no tiene por qué ser brusca ni tajante, pues de ser así lo único que resultará será un niño(a) dependiente en la búsqueda perpetua de dicha conexión. Por su parte Adrienne Rich ${ }^{13}$ indica que todas las teorías psicoanalíticas señalan que la madre debe dejar que el infante se vaya en beneficio del niño(a), pero la madre necesita que se vaya también por el bien de ella misma.

En los cuentos que nos ocupan la simbiosis se ha roto sin preámbulos; la niñez de las protagonistas se ve marcada por la soledad, el aislamiento, la incomunicación y la dolorosa indiferencia de la madre. Por tanto, la hija inicia una afanosa lucha por ganar la atención de quien desempeñe el rol materno. "La niña Elvira", de Cristina Pacheco, presenta una madre violenta que manda 
a su hija a traer agua para lavar los trastes. La niña se demora debido a que la caída del líquido es escasa; lo anterior es motivo para que la madre amoneste y hasta golpee a la pequeña. Ya en la casa el padre, que dormitaba, se enfada con la esposa, quien se quemó mientras cocinaba y continúa regañando a la niña debido a que no se da prisa para auxiliarla. Finalmente, ambos se marchan dejando a la hija sola.

Elvira queda sola. Ya no hay gritos. Los muebles desvencijados, los trastos sucios parecen horriblemente muertos. Sólo ella gime quedito, como si no quisiera romper lo único que le han dejado sus padres: la soledad. ${ }^{14}$

En "La moneda de plata", de Carmen Báez, presenciamos a una niña que fantasea con las posibilidades que le ofrece el encuentro de una moneda y decide, finalmente, renunciar a los beneficios personales que podría obtener para comprarle un trozo de tela a su madre, ya que esta anhelaba un delantal; sin embargo, al regresar a la casa no es bienvenida debido a su tardanza.

Tímidamente, ella se atreve alargando la mano:

- Esto... es para ti...

- ¿Para mí? ¡Sinvergüenza! ¡Descarada! ¡No quiero nada!

Toma la madre el paquete, lo arroja al suelo y con la punta del pie lo lanza hasta el fogón donde comienza a arder en llamas rojas. Antes de que la niña vuelva de su asombro, la mujer, blandiendo una vara de membrillo, elástica y delgada, descarga sobre el azorado cuerpecito una lluvia de azotes.

- ¡Sinvergüenza! ¡Todo el día le estuve pidiendo a Dios que volvieras hoy para matarte a palos! ${ }^{15}$ 
Ciertamente muchas veces la relación se mantendrá gracias a los mecanismos que una y otra emplearán para enmascararse: el engaño, la desconfianza, el fingimiento, la evasión, la manipulación etc. El doble lenguaje es usado por unas y otras, lo que se debe y puede decir ahoga las verdaderas ideas, lo que se desea desesperadamente confesar. Las protagonistas madres e hijas se buscan, pero idealmente. En su imaginación construyen una relación afectiva satisfactoria con una madre o con una hija que se apegue a sus expectativas, una que sí las comprende, las quiere plenamente y no las tortura señalándoles sus fallas o marcando sus diferencias y sí uniéndose en un diálogo de conocimiento y respeto.

"La tía Carlota", de Guadalupe Dueñas, cuenta la historia de una niña que ha sido llevada a vivir con su tía, pues sus padres tienen planes de viajar y no pueden hacerse cargo de ella. La pequeña se siente sola en ese mundo extraño en el que la tía le reprocha la conducta de su cuñada; en Navidad los padres van a visitarla, aunque después se vayan sin despedirse. Finalmente, después de que la niña sufre una crisis de tristeza y desamor, la tía procura reconciliarse con ella.

Los ojos de mi madre son como un trébol largo donde hubiera caído el sol. La sorprendo por los vidrios de la envejecida puerta. Baila frente al espejo y no le tiene miedo al Cristo. Los volantes de su falda rozan los pies ensangrentados. La contemplo con espanto temiendo que caiga lumbre de la cruz. No sucede nada. Su alegría me asusta y sin embargo yo deseo quererla, dormirme en su regazo, preguntarle por qué es mi madre. ${ }^{16}$

Nancy Friday ${ }^{17}$ menciona que uno de los mecanismos de los que se vale una jovencita para controlar su enfado causado por una madre castrante es desarrollar una serie de fantasías 
románticas que la llevan a pensar que hubo un error y no fue entregada a sus verdaderos padres, con los que seguramente sí sería feliz.

La idealización es un remedio falso, tarde o temprano se fracturará. Aunque son más los factores que las unen que los que las dividen, por el simple hecho de ser mujeres y vivir múltiples experiencias comunes la separación es inevitable. Este distanciamiento a veces la madre de antemano lo provoca o la hija crece y la escuela, el trabajo, el matrimonio, colaboran para que tome otros caminos, pero no "nuevos caminos", pues a pesar de que la hija teme reproducir el modelo femenino que observó en su madre y decide ir en sentido contrario, por el desprecio y a veces horror que este le produce, en repetidas ocasiones despertará empantanada en él.

La desunión se efectúa no necesariamente en forma de una lejanía física absoluta; las protagonistas pueden vivir en la misma casa sin por ello estar unidas. Además, esta ruptura en sus relaciones no es tajante, ambas regularán sus conductas en función de la otra, esté o no presente.

En las familias pobres, la rutina de la vida cotidiana y las carencias llenan el ambiente de frustración. La incomunicación se une a la violencia que no solo se manifiesta en un lenguaje agresivo de quien detenta el poder, en este caso la madre; además, el maltrato físico acompaña el castigo materno. Como señala Rich ${ }^{18}$, en el patriarcado el amor materno debe ser constante e incondicional, el amor y la cólera son incompatibles; la ira de la madre es reprobable porque amenaza la institución de la maternidad. A la niña se la trata como a una persona adulta, tiene responsabilidades que comparte con su madre, ambas desempeñan las labores del hogar como dato evidente de que siguen siendo responsabilidad exclusiva de las mujeres, a quienes se minusválida por considerar que su trabajo es improductivo. En las familias burguesas la madre ignora a la hija, quien como consecuencia le profesará rencor y desprecio y se refugiará en la figura femenina que mejor se ajuste a sus necesidades afectivas. 


\section{Madres sustitutas}

La relación con las abuelas, las tías, las sirvientas, que desempeñan en determinado momento el papel de madre, generalmente es alentadora; sí llegan a darse diferencias pero nunca tan dañinas ni violentas como con la madre. La sustituta da y recibe amor, abre la comunicación, la niña o la adolescente confía en ella.

"Unión familiar", de Coty Hernández Bravo, da cuenta de una joven adolescente de diecisiete años que nos narra la soledad en la que vive y la ausencia de confianza hacia sus padres, por lo que recurre a la señora del servicio para contarle los planes que tiene de irse a Acapulco con su novio:

Ni decírselo a mi mamá; siempre está de jeta y haciéndose la mártir para manipularnos. Pero eso sí, no pasa un día sin salir. De la iglesia al masaje, y de sus amigas de canasta a sus escapadas. No nos pela. ${ }^{19}$

En "Marichú", de Beatriz Espejo, la empleada doméstica funge como madre sustituta de la niña que narra la historia. La interacción de la protagonista con la sirvienta es afectiva, cálida, mientras que a su madre la ve ajena, una mujer que ha sido engañada por el marido con una costurera que la propia Marichú recomendó. Se da una dolorosa separación debido a que Marichú intenta vengar el honor mancillado de su patrona, pero esta no la defiende cuando el marido la deja sin empleo; la niña sentirá la cobardía de su madre como una traición personal.

¿Por qué te vas? ¿Por qué te vas si prometiste quedarte junto a mí? -nada contestó -. ¿Por qué dijiste que Dios no permitiría esta desgracia de tu abandono? -insistí. ${ }^{20}$ 
En "Canción de cuna”, de Inés Arredondo, la abuela se hace pasar por madre de la nieta, poco antes de morir la madre le confiesa a su hija la verdad, esta verdad será traumática para la niña. [...] el que su madre no se le entregara más que en unas relaciones secretas, casi pecaminosas, la mantuvo informe, fetal, sin luz. Lo único cierto era la figura segura y bondadosa de la abuelamadre que se daba sin tenerlo que hacer, y sin haber pecado. ${ }^{21}$

Las madres sustitutas participan del reconocimiento y el cariño de las protagonistas a las que a veces su madre les niega su amor si no completamente, sí por largos periodos. Este abandono, más doloroso en la niñez, queda escrito de forma indeleble en la mente de la pequeña, quien muchas veces retornará a buscar en su infancia lo que le falta en su juventud y vejez. La separación de esta forma no funciona como un proceso de crecimiento que permite definir rasgos propios de la personalidad, sino que será la espina que herirá las relaciones entre madre e hija por mucho tiempo.

\section{Modelos no canónicos de madres e hijas}

Algunas hijas no se someten al modelo de sumisión y respeto hacia la madre y a esta la invaden sentimientos de duda o culpabilidad por no tener una hija "normal". Lo anterior llega a provocar discusiones entre los padres, quienes se achacan uno al otro la responsabilidad genética de ese "pequeño monstruo".

En "Las muñecas" nos enteramos de la preocupación de una mujer porque su hija no es como las demás niñas, pues no le gustan las muñecas y por tal razón la madre la lleva al psicólogo. Durante el desarrollo de la trama sabemos que en realidad la madre sufrió un trauma de niña debido a que cierta noche recostó a su muñeca, que por cierto cerraba los ojos, y al regresar esta los tenía abiertos, lo cual la aterrorizó, así que el hecho de que a su hija no le agraden estos 
juguetes le crea miedo.

- No es una niña como las demás, a todas las de su edad les gustan las muñecas ¿por qué a ella no?...

-Es lo que más amo en el mundo y me duele saberla enferma, ver que no es normal. ${ }^{22}$

La ira de las hijas contra las dudas que sus madres tienen cobra formas insospechadas y se origina una lucha que no beneficiará a ninguna de las partes y en cambio creará abismos imposibles de salvar; el cuento "La tía Carlota" nos ofrece un ejemplo.

Cuando cesa de bailar sólo tiene ojos para mi padre. Lo besa con estruendo que me daña y yo quiero que muera. ${ }^{23}$

En el modelo convencional madres e hijas interactúan bajo un manto de armonía. Cuando dicho modelo no se ajusta a la experiencia de la hija, esta sufre sentimientos de culpabilidad que generan odio y, tal como señala Pilar Hidalgo ${ }^{24}$, un deseo -en mayor o menor medida- consciente de que la madre muera.

El cuento titulado "Abril", de Rosaura Barahona, narra la historia de una infante que no se ajusta al paradigma de una niña "normal". Su madre observa intranquila cómo su hija rompe los esquemas; finalmente, la hija se marcha al bosque, lugar que eligió como suyo. "Serena", de la misma autora, permite observar una niña "marimacho", cuya madre la esperaba con ansia pues llegó después de seis varones; sin embargo, la hija se resiste a amoldarse al canon que le es impuesto, aunque una vez que es adulta lamenta no haber estado a la altura de las expectativas de su madre. La primer cita corresponde al cuento titulado"Abril" y la segunda al cuento "Serena". 
Un día, sin embargo, llegó la hora de meter mano al fogón y de abrir el corral. Su madre le enseñó a amasar el pan que los demás se comerían. Abril mezcló los ingredientes en las medidas señaladas y en el orden preciso. Pronto se aburrió. Quiso mezclar más o menos de tal cosa, omitir un ingrediente, sustituir, añadir, rebajar. La madre la miraba extrañada. Por qué insistía en complicar todo cuando sólo debía repetir una receta infalible que había permanecido en la familia durante años. ${ }^{25}$

Serena seguía jugando luchas, policías y ladrones, vaqueros y tochito sin que los juegos de té, las vecinas invitadas a jugar a las comiditas, las muñecas parlantes y los canarios hicieran nada por acercarla a la femineidad, según el concepto de su madre, tías, madrina, abuelas y vecinas. ${ }^{26}$

El cuento "Trazos", escrito por Amelia Domínguez, narra la historia de una niña que sufre constantes enfrentamientos con su madre, ya que siente que siempre está enojada con ella, por lo tanto le apoda "la señora Furia", pues la pequeña se niega a hacer lo que la madre le señala. El castigo no se hace esperar, pero tampoco la venganza.

Yo lo hago al revés: cuando Furia compra alguna muñeca que dice que es de porcelana y que está muy bonita, voy yo y le rompo una mano, un pie, o la despostillo. Sus muñecos de peluche se los mojo para que se vean todos lacios, y corto las flores de su jardín para deshojarlas. Claro que después de eso no me puedo sentar en varios días. ${ }^{27}$ 
Tal parece que la relación con la madre se perfila como una relación de autoridad, de represión y por tanto de resentimiento. La actitud de la hija se torna terriblemente violenta contra la madre, desconstruye la figura de esta y se rebela contra el modelo de femenidad que representa. La ira desmedida es el resultado de años de una educación represiva. Nancy Friday ${ }^{28}$ hace énfasis en esta problemática e indica que cuando alguien nos enseña a reprimir todos nuestros impulsos, a menos que hayamos nacido con un temperamento pasivo o estemos enfermas, generamos un profundo rencor contra la persona que nos obliga a inhibir tantas expresiones auténticamente propias.

Aunque las madres respondan tratando de defenderse, la lucha será desigual, pues la mayor parte de las ocasiones terminarán callando. Algunas madres se niegan a seguir un modelo que encadena su juventud y madurez al cuidado de otros y otras. Se rebelan a someterse a una vida rutinaria que no abarca más allá del perímetro delimitado por la cultura, se resisten a ser lo que Rosalva Lili Vargas define como "mujer gallina".

Esta mujer-ave que podría significar "cierta libertad" está atada a la tierra por su redondez, por sus tradiciones, por sus creencias, por las supersticiones que le "vacía encima" el modelo patriarcal. ${ }^{29}$

Para Hirsch (1989) hay múltiples diferencias dentro de lo femenino y por lo tanto dentro de lo maternal, así como diversos patrones entre las tramas maternales y los relatos de tramas convencionales; sin embargo las madres no canónicas son la minoría. Por ejemplo, en el cuento titulado "Las siete ya van a dar", de Rosa Nissán, vemos a una mujer madura, divorciada, nuevamente enamorada, pero que dedica su vida ya no solo al amor sino a su propio crecimiento 
intelectual y laboral, que rompe con todos los modelos establecidos pues increíblemente es una escritora, asunto que su hijo e hijas no ven como "normal".

-Es el colmo madre, las mamás de mis amigas reúnen a sus hijos, los invitan a comer todos los domingos, mientras tú, hasta en día de madres te fuiste de fin de semana -acusa Vicky-además Pepito tuvo cuatro días de calentura y ni te enteraste. Eres una egoísta. ${ }^{30}$

\section{Hijas vs madres. Enfrentamientos y reencuentros}

Nancy Friday ${ }^{31}$ señala que la ira es un mecanismo que une a la hija con la madre, porque retarda la separación como consecuencia del profundo arraigo de la imagen materna en los pensamientos de la hija. Madres e hijas se suscriben en un círculo vicioso de represión-sacrificio-resentimiento, ello degenerará en una madre enemiga de su hija adulta, y tal como señala Hirsch $^{32}$ en la matrofobia, que no es el miedo a la madre o a la maternidad sino a convertirnos en nuestra propia madre, atrapada en las instituciones patriarcales que anulan su personalidad, con la colaboración de ella misma para preservar el orden establecido transmitiendo a sus hijas de modo "natural" la pasividad y la sumisión.

El cuento "Cabecita blanca" en primer término y después "Enigma" nos permiten ejemplificar la agresión velada en que llegan a vivir ambos personajes.

Cuando Lupe se quedaba, porque no tenía donde ir, tampoco era posible platicar con ella. Respondía con monosílabos apenas audibles y si la señora Justina la acorralaba para que hablara adoptaba un tono de tal insolencia que más valía no oírla. ${ }^{33}$

"Enigma" narra el reencuentro que viven una joven y su madre cuando muere el padre de una 
rara enfermedad.

Quisiera acercarme a ella, pero no me atrevo ; tal vez surja algo que disipe nuestras incógnitas, sin embargo no encuentro nada que nos pueda acercar; posiblemente ella acuda a esas palabras sordas y difíciles en busca de evasiones, como si no le importara mi dolor. ${ }^{34}$

En "La última cena", texto escrito por Cristina Pacheco, presenciamos la discusión de Josefina con su hija Elvira. Entre las dos administran una cocina económica y la madre se empeña en fiarles a los albañiles, quienes abusando de la buena voluntad de esta muchas ocasiones se van sin liquidar sus deudas. Josefina está enamorada en secreto de uno de los trabajadores, Alejandro, que tal como Elvira teme se ha marchado adeudando sus alimentos.

-¿Cuándo vas al mercado? Yo siempre me friego en Jamaica, no te hagas mamá.

- Pues sino quieres ¡No vayas! Ya estás bastante grandecita como para que sepas tus obligaciones.

Si no quieres ayudarme, no me ayudes. Haré las cosas sola, como pueda... - Josefina no encuentra nada más qué decir, tartamudea y al fin se pone a llorar. ${ }^{35}$

“Un error de apreciación” de Teresa Dey nos permite ingresar a la casa de doña Dolores y de su hija María. Esta última se resiste a hacer lo que su madre le indica como lo más adecuado, lo más prudente, lo más femenino. La hija se casa enamorada de un hombre que, curiosamente, cumple las expectativas de la madre; la noche de la boda el nuevo marido se comporta como un "macho" al que solo le interesa cumplir con sus deberes conyugales para después dormir. En el ejemplo presenciamos el momento en que una amiga de la familia se dispone a peinar a la futura novia:

- ¿Cómo quieres que te peine?

- Con el cabello suelto, por favor, Lucy... 
-¿Cómo que suelto? ¿Cuándo se ha visto a una novia con los pelos al aire? ¿De dónde piensas sujetarte el tocado? Se te va a caer con el peso del velo y vas a dejarlo a media iglesia, y qué van a decir Iván y su familia, ya ves que son tan finos. ¡No!, Lucy hazle un chongo de gajos.

- Pero, ma, ¿cómo me voy a desenredar el cabello en la noche?

-Pues desenredándotelo, o te lo lavas y ya. Tú nada más estás pensando en, pensando en... en la noche ¿Eso fue lo que te enseñaron las monjas ?

- No, ma, por desgracia, las monjas me enseñaron inglés, taquigrafía, historia pero de sexo, nada. Eso lo voy a aprender de ahora en adelante...

-Niña, no seas lépera- respondió la madre con intención de darle un bofetón; pero se contuvo, qué iban a decir los suegros de su hija. ${ }^{36}$

Aunque muchas veces no puedan dar rienda suelta a su cólera, por temor a sufrir la pérdida de la otra, lo cierto es que la ira, la frustración y la humillación están presentes, aislándolas. No es solo el distanciamiento propio que marca la brecha generacional, sino la inevitable búsqueda de la separación. Las madres en los enfrentamientos con las hijas se muestran más tolerantes y flexibles, en cuanto a su lenguaje, pero continúan aferradas a sus ideas. Las hijas buscan imponerse, invertir el rol y enseñar a sus madres un nuevo modelo.

\section{Reencuentro}

Después de algún tiempo -a veces son años- de no verse ni hablarse sino esporádicamente, madre e hija se reencuentran. Ambos personajes se analizan con ojos nuevos. Posiblemente reanudarán relaciones o confirmarán su separación. En el cuento titulado "Enigma”, ya antes señalado, madre e hija entablan una nueva interacción debido a la muerte del padre.

Se lleva a cabo un dúo que sólo la noche le es dado escuchar. No sé quién de las dos ha pronunciado 
la primera palabra. Las que siguen, se encadenan para no darle cabida al silencio. Solamente le permitimos un espacio al suspiro que exhalamos. Fue ella quien cerró el diálogo.

- No te angusties tanto, hacía más de diez años que tu padre no me tocaba. ${ }^{37}$

En el cuento "Lo que no se comprende" vemos a madre e hija separadas por un secreto. La niña observa en la casa un "ser extraño", pero nadie le dice que es su propio hermano. Un día la madre descubre a Teresa viendo al niño con mucha curiosidad y la regaña; de este acontecimiento deriva una separación que será superada cuando la madre, que estaba embarazada, dé a luz otro niño y compruebe que está sano. Adrienne Rich ${ }^{38}$ enfatiza que no hay indiferencia o crueldad que se pueda soportar menos que las de nuestras madres.

En la casa entera se sentía alivio y bienestar, y hasta dejaron de vigilarla. Su madre la acariciaba cuando ella ponía un dedo para que Benjamín jugara con él, y sentía muy claramente que la quería otra vez. ${ }^{39}$

La muerte o el inicio de una vida son factores que obligan al autoanálisis y crean oportunidades para redefinir los afectos. Los lazos íntimos entre madre e hija resisten múltiples cortes, pero casi siempre se regeneran, particularmente cuando, como veremos a continuación, la hija vive la experiencia de la maternidad.

\section{El parto como testimonio}

Un punto de interés recurrente en muchos de los textos es el embarazo y el parto -con todos los mitos que los rodean- como huellas que marcan en la vida de las protagonistas un "antes" y un “después”, para vivir con la eterna duda de si valió la pena. Se manifiestan como experiencias únicas, de extrañamiento con el propio cuerpo y con el "yo". Sensaciones nuevas, temores y 
crisis estrangulan la vida de las protagonistas aguijoneándolas casi hasta grados de locura. El organismo cobra una sensibilidad terrorífica. El cuerpo toma un nuevo significado, muchas veces doloroso, antierótico, por lo que la mujer parece desempeñar el papel de una incubadora y nada más. Adrienne Rich señala que la maternidad es una experiencia que además se aprende mediante la disciplina rigurosa de aquellas cualidades que se suponen $<<$ innatas $>>$ : paciencia, sacrificio, voluntad para repetir sin descanso las pequeñas tareas rutinarias para socializar a un ser humano.

Ser $<<$ madre $>>$ implica una presencia continua, que dura por lo menos nueve meses, y más a menudo años. La maternidad se conquista, primero a través de un intenso rito físico y psíquico de paso -embarazo y parto-, y después aprendiendo a criar, lo cual no se sabe por instinto. ${ }^{40}$

Los cuentos nos revelan que en las bodas, los embarazos y los partos, las "otras mujeres" se incorporan a un rito ancestral: las suegras, abuelas, tías, hermanas y, por supuesto, la madre, ofrecen consejos y asistencia a la nueva esposa y futura madre. El nacimiento de las hijas muchas veces no es visto con buenos ojos, a menos que ya haya muchos varones en la familia. La madre inicia un Viacrucis con su hija a cuestas, pues desde el momento de su nacimiento no solo el padre, sino hasta la comunidad la señalan como una decepción porque la madre ha procreado -como si de ella dependiera el sexo de la hija- una mujer. En el cuento titulado "La madre", de Angelina Muñiz, asistimos a un monólogo donde una mujer expone sus reflexiones respecto al embarazo y el momento del parto.

Recordaba las palabras de mi madre enseñándome que ése era el estado perfecto, que me sentiría en paz con el mundo, que advertiría mi lugar exacto en la vida, que iniciaba un círculo de amor, que podría se parte del más insignificante símbolo de la creación. ${ }^{41}$ 
Elizabeth Badinter ${ }^{42}$ indica que existe la creencia de que una vez que una mujer se ha convertido en madre automáticamente encuentra todas las respuestas a su nueva situación. Como si fuera una manifestación automática que se encuentra latente y después del parto se disparara. Si la procreación es natural se piensa que por lo tanto debe corresponderle una actitud maternal determinada.

"Widad", de Rosaura Barahona, es la historia de una joven que debe someterse a una tradición que obliga a las mujeres de su comunidad a pedir perdón al marido por haber concebido una hija y no un varón. El pueblo da el pésame al marido "perjudicado" por su "inútil" esposa.

$\mathrm{Al}$ final a punto de desmayarse, fue ayudada por las tres mujeres.

"Es una niña", dijo la madre con tristeza. Widad empezó a llorar sin fuerza y apenas suplicó:

- Madre, por favor, ayúdeme a decírselo a Adil.

- Eso es obligación tuya.

-"Se pondrá furioso", dijo Widad sin dejar de llorar mientras tomaba la criatura entre sus

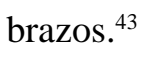

De forma recurrente, el proceso del embarazo y el momento culminante del alumbramiento es descrito como un proceso de auto-conocimiento e introspección. El cuerpo sufre una metamorfosis y obliga a la embarazada a mirarse a sí misma y descubrir sensaciones y sentimientos nuevos que despiertan una diferente mirada de la realidad. El feto creciendo dentro se torna una obsesión, una invasión en el cuerpo femenino de un ser desconocido y amorfo. El cuento "La madre" revela la desmitificación de una de las experiencias femeninas que continuamente se trata como 
dolorosa, pero feliz.

El médico me felicitó. Las enfermeras me felicitaron. Mis amigos también. Pero yo no me sentí feliz. Desde el embarazo había dejado de reconocerme: era otra para mí. ¿Qué le había pasado a mi cuerpo? Peor aún: ¿por qué yo era otra?44

"Joven madre", de María Luisa Puga muestra una joven que sufre varias crisis antes y después del parto. Como consecuencia intenta suicidarse saltando por una de las ventanas del hospital junto con su hija recién nacida; la madre sobrevive pero la hija no.

Porque el doctor decía que mi embarazo iba bien, que mi salud era buena. Y si le decía que me sentía extraña, me decía es normal, es la primera vez. Y yo me obligaba a creerle. Pero arrastré ese cuerpo conmigo cada vez con más pánico. Sintiendo que mi voz se quedaba más y más abajo. ${ }^{45}$

La siguiente cita es del cuento "Canción de cuna" ya mencionado.

Y grita y sigue gritando. Empuja con las dos manos el vientre apenas curvo, lo oprime, trata de suprimir, de aquietar siquiera al habitante del pantano que es de pronto su vientre. ${ }^{46}$

Una vez que la hija vive la experiencia de la maternidad mira a su progenitora con una nueva mirada, la tensión en cierta medida se relaja, comparten nuevamente una experiencia, un dolor común las une. A partir de ese momento muchas madres volverán los ojos a sus hijas para ayudarlas en la educación de las nietas y los nietos. Las abuelas en repetidas ocasiones jugarán el 
rol de madres sustitutas. En algunos cuentos la figura de la abuela llega a ser tan fuerte que logra desplazar a la de su hija y las nietas la ven como una mujer fuerte y decidida.

El discurso literario muestra una diversidad de figuras maternales que dan cuenta de la pluralidad de la experiencia materna. Las madres narran desde su particular perspectiva su experiencia del parto fuera de lo que debe ser y lo que efectivamente es para cada mujer.

\section{Las figuras masculinas y su participación en la relación madre e hija}

Las figuras masculinas (padre, hermano, novio, amante) sufren un desplazamiento. El discurso de las hijas se centra en la madre, sin embargo cuando surgen como figuras poderosas separan a madres e hijas. El padre se muestra en múltiples ocasiones como un hombre castrante y machista al que solo le interesa ver satisfechas sus necesidades y madre e hija están para complacerlo, dispone de la vida de las protagonistas; el hermano pasa a reproducir el papel del padre y se convierte en otra causa de separación para las protagonistas, pues la madre abandona a la hija por atender a los varones, al fin y al cabo es mujer, debe aprender a valerse por sí misma. Pocos padres aceptan que su esposa haya dado a luz una mujer, pues el nacimiento de una niña es un motivo para despreciarla.

"Zhu" expone la mirada retrospectiva de Wu-Lin, quien al ver a su sobrina nadar en el fondo de una alberca, la niña participa en las Olimpiadas, recuerda el nacimiento frustrado de su hija.

Desfallecida intentó levantarse cuando la partera cortó el cordón umbilical pero su esposo se lo impidió. Enderezó la cabeza y alcanzó a ver antes de desmayarse, como la mujer con las manos ensangrentadas sumergía en la tina a su hija y la sostenía con firmeza en el fondo.

Wu-Lin recobró el conocimiento cuando ya no había ningún rastro de la niña. Jamás supo 
en dónde la habían enterrado. Su llanto fue inútil. El padre murmuró que se habían ahorrado muchos sufrimientos, especialmente su hija. Con un poco de suerte, el próximo sería varón y Wu-Lin olvidaría. ${ }^{47}$

“Tres nudos en la red” muestra la desilusión que causa el nacimiento de Águeda.

El nacimiento de Águeda produjo una decepción -mitad consternada, mitad satisfecha del vaticinio cumplido- entre los miembros de la familia Sanromán. [...] Tuvo una hembra y como si no fuera suficiente, la melindrosa se dio el lujo de quedar imposibilitada para concebir de nuevo. ${ }^{48}$

"Widad", ya citado, señala el desprecio que sufre la madre por no haber parido un varón. La mujer hizo un gesto para ofrecer la niña al padre mientras le decía: "Es muy hermosa”, pero Adil continuó mirándola sin posar los ojos en su hija. "Ni para eso sirves; de nuevo me has puesto en vergüenza ante mi familia y amigos" Widad le pidió perdón arrepentida y prometió que la próxima vez tendría un varón. "Si no es así, te repudiaré”, aseveró Adil y salió sin decir nada más. ${ }^{49}$

La niña llega ser mucho tiempo solo hija de su madre, pues no pocas veces el padre es el primero en rechazarla declarada u ocultamente, inflingiendo un castigo a la esposa que "le negó" el hijo a quien poder heredarle todo lo que el progenitor tiene y que además garantizaría la continuidad de su apellido. Las niñas son las primeras víctimas del infanticidio. Lloyd de Mause ${ }^{50}$ sugiere que el 
desequilibrio estadístico de los hombres respecto a las mujeres desde la antigüedad hasta la Edad Media no fue más que el resultado del asesinato común de las niñas recién nacidas.

Una vez que la niña crece, el padre presiona a la madre por causa de la conducta de la hija; la madre a veces parece estar coludida con el patriarcado, ya que a su vez empieza a rechazar a la joven. Las hijas sienten que las madres eligen al padre por encima de ellas y que sacrifican las necesidades de la hija en aras de las teorías y deseos del padre, por tanto sueñan con huir del hogar, nunca se enfrentan directamente al progenitor como llegan a hacerlo con su madre porque ciertamente la figura de esta logra adquirir dimensiones más aplastantes, se torna el enemigo a vencer y un objeto de exploración que domina los relatos femeninos.

La identificación sexual con la madre y la búsqueda de una personalidad propia constituyen dos ejes que se entrecruzan y persisten a lo largo de todo el corpus que hemos examinado. Junto con la madre, la niña se iniciará en la educación femenina. Desde su nacimiento ropa, juegos y juguetes -que preludian con décadas de anticipación su potencial materno-, así como su comportamiento, responderán a patrones que la madre se verá precisada a inculcar en su pequeña. Algunas niñas se niegan a seguir ese patrón y prefieren comportarse de una forma que la madre trata inmediatamente de ajustar a lo que se espera de una niña. Una vez que esta puede desempeñar las labores del hogar, la madre la inicia en las rutinas del locus familiar (que será su principal espacio de movimiento, además de la escuela) ya que algún día formará su propia familia y debe demostrar que la madre cumplió bien "su misión": enseñarla a ser una "mujer completa", aun cuando el desempeño de las labores en el hogar no sean reconocidas como un trabajo, no reciban ninguna remuneración, y el marido llegue a pensar que a cambio de nada está obligado a mantener a la esposa. La principal preocupación de las madres es casar a sus hijas con los hombres adecuados. La religión cumple un papel preponderante para enseñar a la joven sus 
obligaciones.

El momento de la menstruación conlleva para las adolescentes nuevas responsabilidades. La educación sexual se efectúa con tropiezos, y la mayor parte de las ocasiones es evadida completamente. La madre oculta una vida, su juventud y sexualidad ha quedado anclada en el pasado, del que no hará partícipe a su hija, la cual a veces sufre iguales temores o deseos. Las citas de los textos elegidos donde se puede observar los puntos expuestos con anterioridad son "Uka" de Rosaura Barahona y "La celda", de Amparo Dávila. En "Uka" se expone el rito de iniciación que "sufre" una joven tras su primera menstruación.

Uka, que seguía sangrando y quejándose del dolor en el bajo vientre, supo que ese día la ayudarían a pasar de niña a mujer. La sangre anunciaba su impureza. Ya no podría jugar con las demás niñas y debería aprender a cuidarse de los hombres, le dijeron. ${ }^{51}$

Su madre casi orgullosa le dijo : "Ahora eres una de las nuestras".

Uka abrió sus ojos negros y rasgados llenos de incomprensión unos segundos. Después se quedó dormida con su primer sueño de mujer. ${ }^{52}$

En el cuento "La celda" se observa a una joven llena de temor y ansiedad pues un ser extraño ha invadido su habitación y, a pesar de todo el pánico que le causa, prefiere sufrir sola antes que enterar a su madre y a su hermana. A su casa acuden con frecuencia Mario, novio de su hermana, y el primo de este, José Juan. Con el fin de escapar del tormento que cada noche la persigue 
decide contraer nupcias con José Juan, pero esta no es la solución a su miedo; la madre jamás se entera pues su única preocupación es casar “bien” a sus hijas.

La señora Camino no pudo evitar unas lágrimas de felicidad, “satisfecha de haber encontrado tan magníficos partidos para sus queridas niñas. ${ }^{53}$

La madre es el primer modelo femenino con el que la hija tiene contacto. Los esquemas de comportamiento y sentimientos asimilados con respecto a la femineidad son resultado de la construcción que, a lo largo de la infancia, la niña hizo de su madre, de ahí que se sentirá, más o menos, satisfecha con su género en la medida que su progenitora le haya transmitido un modelo positivo o negativo del mismo. No hay un modelo único y universal de las relaciones entre madres e hijas. El dominio del discurso lo poseen las hijas y la madre pasa a ser el objeto de ese discurso en el que la hija la busca. Tal como señala Hirsch ${ }^{54}$ la relación no conflictiva de la hija se da con una amante, es decir, con una mujer que no sea la madre, mientras que se marca un distanciamiento con respecto a las figuras masculinas. Es indispensable la voz de la madre para comprender el entramado de relaciones que ambas construyen, pero esta manifestación apenas si se vislumbra.

En el conjunto de cuentos seleccionados emergen continuamente las siguientes interrogantes: ¿Quién es esa mujer a la que llamo madre? ¿Quién es mi hija? ¿Quién soy yo? ¿Soy la madre? o ¿Soy la hija? ¿Soy ambas? ¿Tú eres yo? ¿Yo soy tú? La aparición recurrente de espejos, de objetos de la juventud de la madre, que llegan a pertenecer a la hija, reiteran la preocupación por redefinir los espacios y tiempos de cada una.

El problema de la construcción de la identidad es descubrir una personalidad propia y auténtica que facilitará la definición de roles, los que en múltiples ocasiones se intercambian. La más 
confundida en este renglón es la hija, quien en principio muchas veces idealiza la imagen de la madre y desea imitarla ${ }^{55}$, sobre todo en la niñez. En la adolescencia cuestiona y revisa el desempeño de la madre, particularmente en cuanto a su interacción con la figura masculina -el padre- y su crecimiento integral; lo que resulta es una imagen que la hija rechaza y busca con afán desprenderse de ella. La madre se convierte así en el patrón de lo que a la hija le desagrada, lo cual significa que denigrará hasta el último reflejo que descubra de su madre en su personalidad, la dolorosa frase es iqué horror, ya me parezco a mi madre!

Por su parte, muchas madres no aceptan que sus hijas sean independiente, utilizan todos los medios a su alcance para mantener a su hija como una extensión de su cuerpo, perpetuar su imagen en ella. El cordón umbilical sigue uniéndolas, aunque cuando la madre no se ajusta al patrón establecido las hijas las condenan. Hirsch ${ }^{56}$ dice que la conexión con la madre es a través de identificación y la lucha contra esta identificación. Así, la palabra identidad es paradójica en sí misma, porque significa simultáneamente igualdad y diversidad y sus contradicciones abundan cuando la noción se aplica a las mujeres.

Las siguientes citas muestran cómo algunas madres no entienden que su hija posee una personalidad propia, que es un individuo con rasgos diferentes a los suyos. A su vez, la mayoría de las hijas busca por todos los medios ser diferente a su madre, sin embargo esta separación, a veces resulta una falacia y acaban reproduciendo el modelo materno. "Respuestas al viento", de Alicia García Villarreal, cuenta la historia de una niña "extraña", pues es muy independiente y ello a su madre le causa terror.

Ella no balbucea mamá, mi mamá, no depende de mí para controlar su cuerpo, no me toma del dedo y me dice 'yo sola'... es que ya está sola, siempre lo ha estado porque no me necesita, nunca me necesitó. ${ }^{57}$ 
En "Las muñecas", la madre se preocupa mucho (al grado de llevar a su pequeña a un psicólogo) porque a su hija no le gustan las muñecas mientras que ella en su niñez las adoró, aunque la verdad es que le ha transmitido a su hija su propio temor inconsciente por estos juguetes. Esta madre no acepta la personalidad de la niña a la que según ama, pero la diferencia la espanta.

Es lo que más amo en el mundo y me duele saberla enferma, ver que no es normal. ${ }^{58}$

En el cuento "La otra cara de la moneda", de Martha Cerda, después de descubrir que su hija ya no es una niña una madre renuncia a ir a trabajar para quedarse a cuidarla.

En medio estaba Maty, con sus paperas marcando el fin de su infancia, de su parecido con mamá. ${ }^{59}$

En "El eterno teatro" de Brianda Domecq, la hija le da a conocer a su madre que participará en una obra "sumamente original" pues los personajes irán improvisando sus textos y por lo tanto “vivirán” las escenas. La obra reproduce fielmente la vida y pasados algunos años la actriz que personificaba a la hija ahora es la madre y la anterior madre ahora es la abuela.

Así evitaré el círculo vicioso de casarme para tener una hija que se casa para tener una hija que se casa... y siempre con la ligera sospecha de que a lo mejor no valió la pena [...] soy diferente a ti: busco algo más. ${ }^{60}$ 
La protagonista sufrirá a su vez la descalificación de la joven que hace el papel de su hija quien disfruta enormemente su éxito, mientras tanto Beatriz llorará y repetirá la misma frase de su madre "no entiendo para nada a esta nueva generación". La protagonista aparece constantemente como agente y observadora, completa el desdoblamiento por la indecisión acerca de la función de "la verdadera mujer". El cuento muestra su fase de independización y éxito en la vida profesional, pero al final se encuentra sujeta al modelo que la impulsó a buscar la diferencia. De esta manera, el cuento toca el tema de la liberación y plantea el dilema de la mujer que quiere trabajar y ser reconocida. Hay cierta amargura en esta protagonista que no acepta el papel tradicional, pero que no logra desasirse de él.

\section{Conclusiones}

Después del análisis de las relaciones entre madres e hijas en cuentos de escritoras mexicanas, es posible llegar a las siguientes observaciones generales. Con respecto a los personajes la voz narrativa que domina es la de la hija. La pregunta que surge es ¿por qué la voz de la madre continúa relegada a un segundo o tercer plano? En esta estrategia narrativa parece que las hijas se encuentran coludidas con el patriarcado. Incluso en los relatos donde prevalece el estilo directo sobre la narración la voz de la hija ocupa mayor espacio y, por ende, mayor tiempo en la trama. En cierto modo la madre continúa en un papel pasivo, apenas se ha liberado de ser el objeto que permite y ayuda (o, en algunos casos, impide) el proceso de individuación de la hija. Permite las interrupciones de la hija y tolera, a veces con demasiada paciencia, múltiples acusaciones; sin embargo, los cuentos de las escritoras españolas muestran madres que toman con mayor frecuencia la voz. 
La figura materna es sumamente importante en la vida de la hija. En la mayoría de los relatos la madre tiene un poder arrollador, determinante para la conducta presente y futura de la hija. El rostro, el cabello, los senos y las manos quedan grabados en la mente de las hijas a fuerza de una minuciosa observación. Éstas describen, con una especie de obsesión, hasta los detalles más insignificantes del cuerpo de la progenitora. Así, la imagen materna invade hábitos, recuerdos, sueños, dudas y terrores de la hija.

La madre se preocupa por la vida presente y futura de la hija. Lo anterior se constituye como una preocupación recurrente y por ello toma características a veces patológicas. La madre teme, por un lado, que la hija no se sujete a las normas establecidas por la sociedad en la que viven, de lo contrario ella será la culpable y no la hija. En aras de esa "misión" la relación se deteriora, pues en repetidas ocasiones la madre se convierte en una sombra que pesa sobre la hija e incluso esta siente que es evaluada por la mirada materna aunque aquella no esté presente. Por otra parte, la madre llega a temer el abandono de la hija, sobre todo adulta, y evita por lo tanto el crecimiento de esta y su contacto con otras personas, de tal manera que el amor evoluciona y adquiere matices de odio. Muchas madres "sugieren" a sus hijas que deben casarse y tener hijos para sentirse plenas y comprender lo que significa ser mujer. Cabe aclarar que este rasgo destaca más en las escritoras mexicanas. Es decir, para las madres que tienen hijas jóvenes la maternidad no fue una elección sino un destino.

Existe entre ambas protagonistas una especie de código secreto, un lenguaje que solo ellas comparten. Sea que se amen o que se odien, ambas protagonistas manejan un lenguaje cifrado, oculto a los ojos de los demás, pero que ellas comprenden muy bien: una mirada, un gesto, una palabra, el más mínimo movimiento y hasta el silencio cobran un significado complejo y completo. Muchas veces no necesitan hablar porque han logrado comunicarse mediante este 
lenguaje silencioso que han practicado durante siglos en los que el mutismo de la mujer (en el cual algunas madres han educado a sus hijas) resulta una cualidad apreciada por el patriarcado. El vínculo que se establece entre madre e hija no se manifiesta a través de aspectos racionales; parece, más bien, una relación cuerpo a cuerpo, ambigua e incierta para otros. De ahí deriva su carácter mágico, inasible e innombrable, su calidad de secreto. Lo anterior prevalece de forma particular en los cuentos de las escritoras mexicanas; en los de las españolas las protagonistas empiezan a reflexionar profundamente con respecto a la relación que sostienen.

Aun cuando la figura materna puede tener características eróticas, llega a detenerse en una imagen carente de atractivo erótico. La ropa discreta, la voz cálida, el cabello recogido suavemente, los gestos mesurados, todo ello viene a ser un símbolo de la madre. Se torna así en "la virgen" intocable e inaccesible que se eleva por encima de las pasiones carnales, esta mistificación la aleja de la hija para quien a veces esta imagen de la madre resulta ambivalente: en la infancia la evalúa como admirable y en la juventud la considera chocante y hasta hipócrita. La hija llega a vanagloriarse de su vida mundana, de su "diferencia".

Las figuras masculinas pasan a un plano secundario o desaparecen de la vida de las protagonistas sin dejar huella. En la mayoría de los relatos analizados las figuras masculinas resultan ausentes o bien secundarias, apenas sirven para fungir como testigos de la interacción de madre e hija o para fracturar su unión, pero no al grado de romperla definidamente. Después de la separación por causa de un hombre, la relación madre e hija permanecerá latente, dormida, pero no muerta. Ni el padre, el hermano o el amante desempeñan un papel que favorezca la reconciliación, sino que llegan a aprovecharse y a obtener algún beneficio de la separación de las mujeres; en diversos momentos muestran una absoluta indiferencia y se mantienen "aparentemente" al margen.

Abundan la ironía, los puntos suspensivos y los paréntesis. Las protagonistas hablan un doble 
discurso, el decir y el no decir, el mostrar y el ocultar. En algunas ocasiones el discurso de ambas llega a ser agresivo, plagado de reproches y humillaciones hacia la otra. La lectora o el lector debe llenar esos vacíos, encontrar los sobrentendidos y la ambigüedad de las palabras que permiten descubrir la riqueza de los "tonos".

Predominan los espacios cerrados, concretamente la casa. La imagen de la madre se mueve en el ámbito doméstico; la hija es quien, la mayoría de las ocasiones, sale de casa para desenvolverse en otro lugar. La escuela o el desempeño de un trabajo remunerado separa a las protagonistas por largos periodos. La vida de la madre queda muchas veces enjaulada en el desempeño doméstico, ese es su reino y ahí ejerce su poder. Aunque empiezan a aparecer algunas madres que no desean dedicar su tiempo por completo a la vida rutinaria del hogar e ingresan al mundo laboral e intelectual (muy pocas son escritoras), resulta claro que nunca se liberan del quehacer lo suficiente como para crecer en otros ámbitos. En este sentido predomina la figura de la madre canónica, pasiva y dependiente, sujeta a la casa y por lo tanto a las labores domésticas. Muchas son sorprendidas por la vejez y la soledad; las hijas e hijos se han ido y las madres no saben qué hacer con tanto tiempo libre (generalmente, el marido ni siquiera se menciona: las abandonó o ya ha muerto).

Dominan los centros urbanos y la clase media. Tanto en los cuentos de las escritoras mexicanas como en los de las españolas las tramas se desarrollan casi todas en lugares citadinos, donde los servicios y las comodidades facilitan la vida de los habitantes; las áreas rurales, los ranchos o los pueblos pasan a segundo plano.

Las protagonistas generalmente pertenecen a la clase media, muchas de estas son apoyadas por nanas o sirvientas que auxilian a las madres en la crianza de las hijas y los hijos, de ahí que las hijas continuamente acusen a las madres de abandono e indiferencia; lo mismo ocurre en las 
clases altas.

En cuanto a los grupos marginados o con menor poder adquisitivo, las madres sufren una doble carga: son esposas de maridos machistas y son pobres. Viven agobiadas por el trabajo, los malos tratos por parte del marido y la carencia de recursos. Mutilan sus ambiciones, se sacrifican por los vástagos. Sin embargo, bajo determinadas circunstancias la ira llega a dominarlas para dar paso a la violencia aparentemente incomprensible que las hace aparecer a los ojos de los demás, incluso de la hija, como "locas", "histéricas" e "intolerantes".

Existe una tradición de literatura escrita por mujeres que exige y merece ser analizada con toda seriedad. Las escritoras mexicanas han sufrido durante mucho tiempo la falta de reconocimiento hacia sus obras, y si llegan a tenerlo suele ir acompañado de cierta condescendencia; a pesar de que las historias de la literatura las dejan fuera sistemáticamente, se han ido abriendo camino.

El incremento paulatino del interés por la literatura escrita por mujeres, principalmente por parte de investigadoras, ha favorecido el rescate y estudio de la producción de diversas autoras, por ello ha sido posible descubrir que mientras la figura de la madre como protagonista es tratada de vez en cuando por algunos escritores, para la escritoras esta cobra mayor fuerza y relevancia. Resulta innegable, por lo tanto, que son las autoras quienes conceden a la madre y a la hija un papel propio y autónomo.

Como han indicado continuamente las teorías feministas, la identidad no debe ser la meta, sino el punto de partida de cualquier proceso de auto-conciencia; sugieren que la comprensión de la identidad por parte de las mujeres es múltiple y aún contradictoria y está más bien determinada cultural que biológicamente. La pregunta medular de la crítica literaria femenina es ¿Quién está ahí cuando una mujer dice "Yo soy"? Es importante reconocer que la identidad femenina está formada por un conjunto históricamente determinado de interrelaciones entre condiciones socioeconómicas y procesos 
ideológicos y culturales.

La literatura escrita por mujeres descubre los múltiples rostros de la relación madre e hija. Tal como señala Rich ${ }^{61}$ hablar de la ambivalencia materna, examinar los conflictos ambiguos y apasionados de la relación madre e hija y el rol de la madre al educar a su hija para la servidumbre, identificar la culpabilidad que sienten las madres ante el fracaso de las hijas, entre otros temas, significa cuestionar los temores y prejuicios profundamente enraizados en la sociedad. Como menciona Hirsch $^{62}$, es indispensable desmitificar los relatos maternales, evitar que continúen como objetos de una búsqueda. La única manera de lograr nuevas maneras de vivir es encontrando una doble voz que exprese una conciencia múltiple de mujer; entonces las feministas construirán una forma de conciencia y de subjetividad que crea y es creada, por la revolución ideológica y social que el feminismo solamente ha comenzado.

\section{(Endnotes)}

1 Notas:

Marianne Hirsch, The Mother/Daughter Plot (Bloomington, Indiana: University Press, 1989), 9.

2 Ibid.

3 Gérard Genette, Figures III (París: Editions du Seuil, 1972), 182-224.

4 Hirsch, 10.

5 Raquel Gutiérrez Estupiñán, Hacia la caracterización de la escritura femenina. La narrativa de Luisa Josefina Hernández. (Madrid: Tesis doctoral publicada en microfichas por la Universidad Nacional de Educación a Distancia, 1996), 4.

6 De acuerdo con Genette el narrador heterodiegético y extradiegético no participa en los hechos que narra, el homodiegético e intradiegético es un narrador en segundo grado que cuenta su propia historia. 
Indexaciones: Repositorio de Revistas UCR, DIALNET, Latindex, REDALYC Directorio y recolector de recursos digitales del Ministerio de Cultura de España, Directory of Open Access Journals.

Diálogos Revista Electrónica de Historia ISSN 1409- 469X. Número especial 2008. Dirección web: http://historia.fcs.ucr.ac.cr/dialogos.htm

7 Rosario Castellanos, Obras completas. Narrativa (México: Fondo de Cultura Económica, 1996), 868.

8 Antonieta Rivas Mercado, Obras completas (México: Fondo de Cultura Económica, 1985), 258.

9 Betriz Espejo, Antología personal (México: Universidad Veracruzana, 1996), 51.

10 Hirsch, 161.

11 Adrianne Rich, Nacemos de mujer. La maternidad como experiencia e institución (Madrid: Cátedra, 1986), 349-350.

12 Nancy Friday, Mi madre/yo misma (Barcelona: Argos Vergara, 1989), 61.

13 Rich, 76.

14 Cristina Pacheco, Cuarto de azotea (México: Secretaría de Educación Pública y Ediciones Gernika, 1986), 18.

15 Carmen Báez, La roba pájaros (México: Fondo de Cultura Económica: 1980), 52.

16 Guadalupe Dueñas, Tiene la noche un árbol (México: Fondo de Cultura Económica, 1992), 12.

17 Friday, 101.

18 Rich, 90.

19 Coty Hernández, “Unión familiar”, (1996)en Las mujeres de la torre, ed. Rogelio Carvajal Dávila

(México: Océano, 1996), 229-230.

20 Espejo, 94.

21 Inés Arredondo, La señal (México: Era, 1965), 92.

22 María de Lourdes Morales Grajales, Desde el espejo que te mira (México: Universidad Autónoma de Chiapas, 1996), 26.

23 Dueñas, 12.

24 Pilar Hidalgo, Tiempo de mujeres (España: horas y HORAS, 1995), 104.

25 Rosaura Barahona, Abecedario para niñas solitarias (México: Ediciones Castillo, 1994), 15.

26 Ibid. 111 
Indexaciones: Repositorio de Revistas UCR, DIALNET, Latindex, REDALYC Directorio y recolector de recursos digitales del Ministerio de Cultura de España, Directory of Open Access Journals.

Diálogos Revista Electrónica de Historia ISSN 1409- 469X. Número especial 2008. Dirección web: http://historia.fcs.ucr.ac.cr/dialogos.htm

27 Amelia Domínguez, Después de tanto silencio (México: Edición personal, 1989), 56.

28 Friday, 100.

29 Rosalía Lili Vargas, "La mujer gallina”, en Filosofia de la Educación y Género, compiladora Graciela Hierro (México: Universidad Autónoma de México, Facultad de Filosofía y Letras, 1997), 194.

30 Rosa Nissán, “Las siete ya van a dar”, en A través de los ojos de ella. Tomo II, compiladora Brianda Domecq (México: Ariadna, 1999), 297.

31 Friday, 249.

32 Hirsch, 136.

33 Castellanos, 874.

34 Morales, 21

35 Cristina Pacheco, El corazón de la noche (México: El caballito, 1989), 35.

36 Teresa Dey, Mujeres transgresoras (México: Océano, 1997), 102.

37 Morales, 23.

38 Rich, 333.

39 Inés Arredondo, Los espejos (México: Joaquín Mortiz, 1988), 72.

40 Rich, 46.

41 Angelina Muñiz, El libro de Miriam y Primicias (México: Universidad Autónoma Metropolitana, 1990), 71.

42 Elizabeth Badinter, ¿Existe el instinto maternal? (Buenos Aires: Paidós, 1991), 12.

43 Barahona, 132.

44 Muñiz, 71.

45 María Luisa Puga, "Joven madre”, en Mujeres en el espejo, recopiladora Sara Sefchovich (México: Folios, 1983), 185.

46 Arredondo, "La señal”, 83. 
Indexaciones: Repositorio de Revistas UCR, DIALNET, Latindex, REDALYC Directorio y recolector de recursos digitales del Ministerio de Cultura de España, Directory of Open Access Journals.

47 Barahona, 151.

48 Castellanos, “Obras completas”, 964.

49 Barahona, 132.

50 Lloyd de Mause, “The Evolution of Chilhood”, en De Mause, The History of Chilhood (Nueva York: Harper and Row, 1974), 25-26, 120.

51 Barahona, 121.

52 Ibid. 123.

53 Amparo Dávila, Muerte en el bosque (México: Fondo de Cultura Económica, 1985), 52.

54 Hirsch, 135.

55 No todas las hijas entran en este cuadro.

56 Hirsch, 138.

57 Alicia García Villarreal, Réquiem (en blues) para una antigualla (México:Premia, 1993), 56.

58 Morales, 26.

59 Marta Cerda, Las mamás, los pastores y los hermeneutas (México: Ediciones Castillo, 1995), 6.

60 Brianda Domecq, Bestiario doméstico (México, Fondo de Cultura Económica, 1992), 49.

61 Rich, 234.

62 Hirsch, 161. 